Supporting information for

\title{
Investigation of Pathway for Water Delivery in Photosystem II Protein by
} Molecular Dynamics Simulation

Koji Ogata1, $\uparrow^{*}{ }^{*}$, Makoto Hatakeyama1, $\uparrow$, Yuki Sakamoto1,2, and Shinichiro Nakamura1

1 RIKEN Cluster for Science, Technology and Innovation Hub, Nakamura Laboratory, 2-1 Hirosawa, Wako, Saitama 351-0198, Japan

2 Department of Biological Information, Tokyo Institute of Technology, 4259

Nagatsuta, Midori-ku, Yokohama 226-8503, Japan

†Present address: Faculty of Pharmacy, Sanyo-Onoda City University, 1-1-1 DaigakuDori, Sanyo-Onoda, Yamaguchi 756-0084, Japan

To whom correspondence should be addressed. Email: ogatak@rs.socu.ac.jp 
Table S1 Modeling region of PSII protein

\begin{tabular}{|c|c|c|c|c|c|c|c|}
\hline \multirow{2}{*}{ Chain } & \multicolumn{2}{|c|}{ Region } & \multirow{2}{*}{ Length } & \multirow{2}{*}{ Chain } & \multicolumn{2}{|c|}{ Region } & \multirow{2}{*}{ Length } \\
\hline & Start & End & & & Start & End & \\
\hline A & 1 & 10 & 10 & $\mathrm{a}$ & 1 & 10 & 10 \\
\hline B & 506 & 506 & 1 & $\mathrm{~b}$ & 506 & 506 & 1 \\
\hline \multirow[t]{2}{*}{$\mathrm{C}$} & 19 & 22 & 4 & & & & \\
\hline & & & & $\mathrm{d}$ & 11 & 11 & 1 \\
\hline $\mathrm{E}$ & 1 & 3 & 3 & $\mathrm{e}$ & 1 & 3 & 2 \\
\hline F & 2 & 11 & 10 & $\mathrm{f}$ & 2 & 13 & 12 \\
\hline $\mathrm{J}$ & 1 & 1 & 1 & & & & \\
\hline M & 35 & 36 & 2 & $\mathrm{~m}$ & 35 & 36 & 2 \\
\hline $\mathrm{O}$ & 3 & 3 & 1 & o & 3 & 3 & 1 \\
\hline $\mathrm{T}$ & 31 & 32 & 2 & $\mathrm{t}$ & 31 & 32 & 2 \\
\hline $\mathrm{U}$ & 1 & 7 & 7 & $\mathrm{u}$ & 1 & 7 & 7 \\
\hline$X$ & 41 & 41 & 1 & $\mathrm{x}$ & 41 & 41 & 1 \\
\hline $\mathrm{Y}$ & 17 & 17 & 1 & $\mathrm{y}$ & 17 & 17 & 1 \\
\hline
\end{tabular}


Table S2 Assignment of UNL ligands

\begin{tabular}{ccl|ccl}
\hline Chain & Residue No. & Substitute & Chain & Residue No. & Substitute \\
\hline A & 420 & DPPG & a & 418 & DPPG \\
B & 635 & DPPG & b & 634 & DPPG \\
D & 409 & Hexadecanol & c & 926 & DPPG \\
D & 410 & DPPG & d & 410 & Hexadecanol \\
I & 101 & DPPG & d & 411 & DPPG \\
J & 102 & Decane & d & 413 & DPPG \\
K & 101 & DPPG & $\mathrm{i}$ & 101 & DPPG \\
M & 102 & Decane & j & 102 & Decane \\
X & 101 & DPPG & $\mathrm{m}$ & 101 & Decane \\
\hline
\end{tabular}

DPPG: 1,2-dihexadecanoyl-sn-glycero-3-phospho 
Table S3. Detail of the constraint for relative distances

\begin{tabular}{|c|c|c|c|c|c|}
\hline Residue & Atom & Residue & Atom & Distance & Constant ${ }^{1}$ \\
\hline D1-Glu189 & OE2 & OEX & Mn1 & 1.8 & 50.0 \\
\hline D1-Asp342 & OD2 & OEX & Mn1 & 2.2 & 50.0 \\
\hline D1-His332 & NE2 & OEX & Mn1 & 2.0 & 50.0 \\
\hline D1-Ala344 & OXT & OEX & Mn2 & 1.9 & 50.0 \\
\hline CP43- & OE1 & OEX & $\mathrm{Mn} 2$ & 2.1 & 50.0 \\
\hline \multicolumn{6}{|l|}{ Glu354 } \\
\hline D1-Asp342 & OD1 & OEX & Mn2 & 2.2 & 50.0 \\
\hline D1-Glu333 & OE1 & OEX & Mn3 & 2.1 & 50.0 \\
\hline CP43- & OE2 & OEX & Mn3 & 2.1 & 50.0 \\
\hline \multicolumn{6}{|l|}{ Glu354 } \\
\hline D1-Glu333 & OE2 & OEX & Mn4 & 2.1 & 50.0 \\
\hline D1-Asp179 & OD2 & OEX & Mn4 & 2.1 & 50.0 \\
\hline W1 & $\mathrm{O}$ & OEX & Mn4 & 2.1 & 50.0 \\
\hline W2 & $\mathrm{O}$ & OEX & Mn4 & 2.2 & 50.0 \\
\hline D1-Ala344 & $\mathrm{O}$ & OEX & $\mathrm{Ca}$ & 2.4 & 50.0 \\
\hline D1-Asp170 & OD1 & OEX & $\mathrm{Ca}$ & 2.4 & 50.0 \\
\hline W3 & $\mathrm{O}$ & OEX & $\mathrm{Ca}$ & 2.5 & 50.0 \\
\hline W4 & $\mathrm{O}$ & OEX & $\mathrm{Ca}$ & 2.6 & 50.0 \\
\hline CP43- & $\mathrm{NZ}$ & $\mathrm{Cl}-1$ & $\mathrm{Cl}$ & 3.0 & 100.0 \\
\hline \multicolumn{6}{|l|}{ Lys 317} \\
\hline D1-Glu333 & $\mathrm{N}$ & $\mathrm{Cl}-1$ & $\mathrm{Cl}$ & 3.4 & 100.0 \\
\hline D1-181 & ND2 & $\mathrm{Cl}-1$ & $\mathrm{Cl}$ & 3.1 & 100.0 \\
\hline D1-Phe339 & $\mathrm{N}$ & $\mathrm{Cl}-2$ & $\mathrm{Cl}$ & 3.7 & 100.0 \\
\hline D1-Asn338 & $\mathrm{N}$ & $\mathrm{Cl}-2$ & $\mathrm{Cl}$ & 3.1 & 100.0 \\
\hline CP43- & $\mathrm{N}$ & $\mathrm{Cl}-2$ & $\mathrm{Cl}$ & 3.4 & 100.0 \\
\hline Glu354 & & & & & \\
\hline
\end{tabular}

${ }^{1}$ Harmonic force constant in the constraints. 


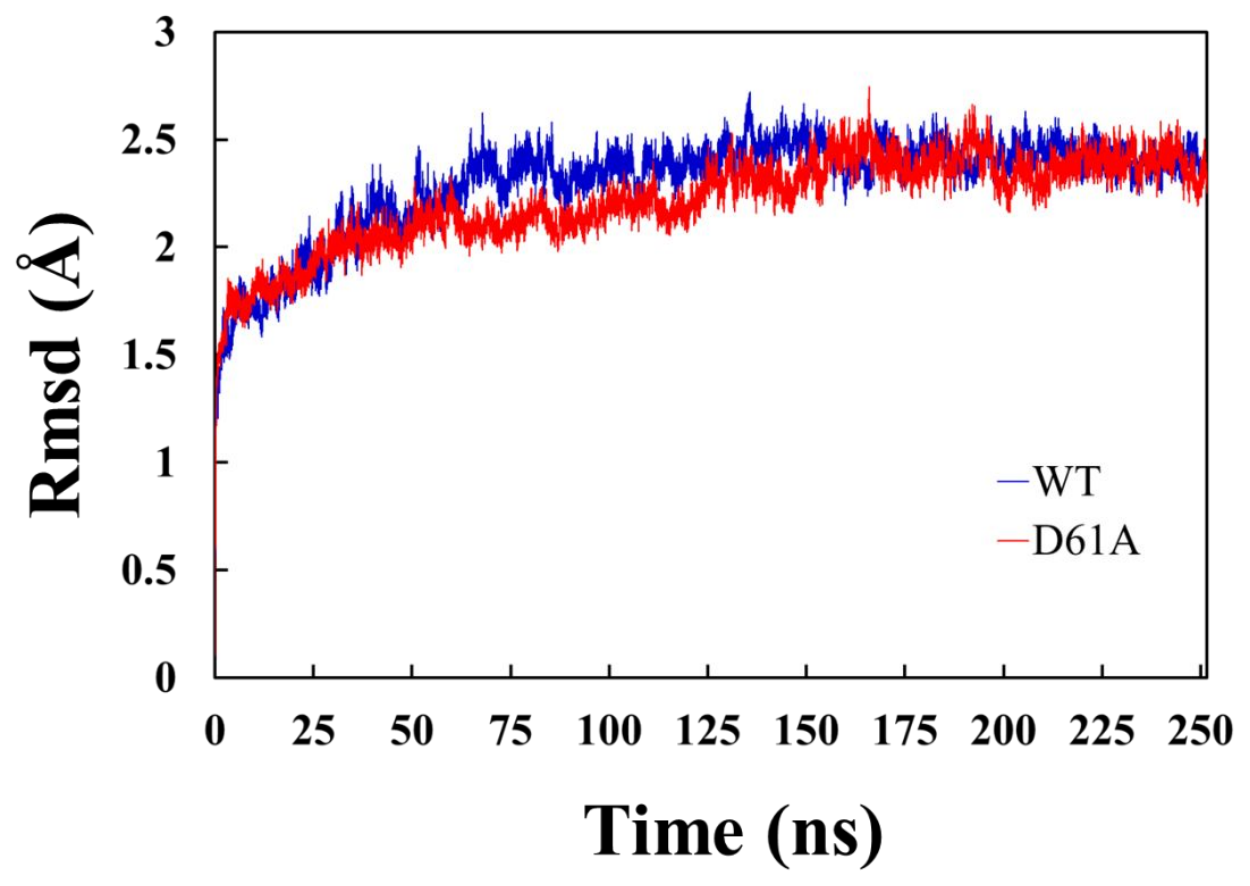

Figure S1. Rmsd vs. time steps of simulation for wild type and D1-D61A mutant colored in blue and red, respectively. 
(a)

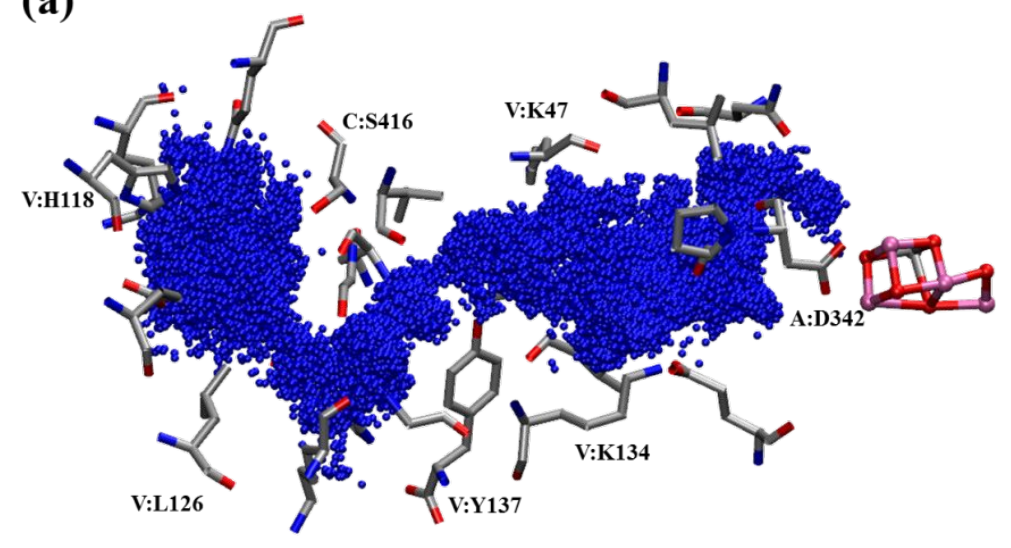

(b)

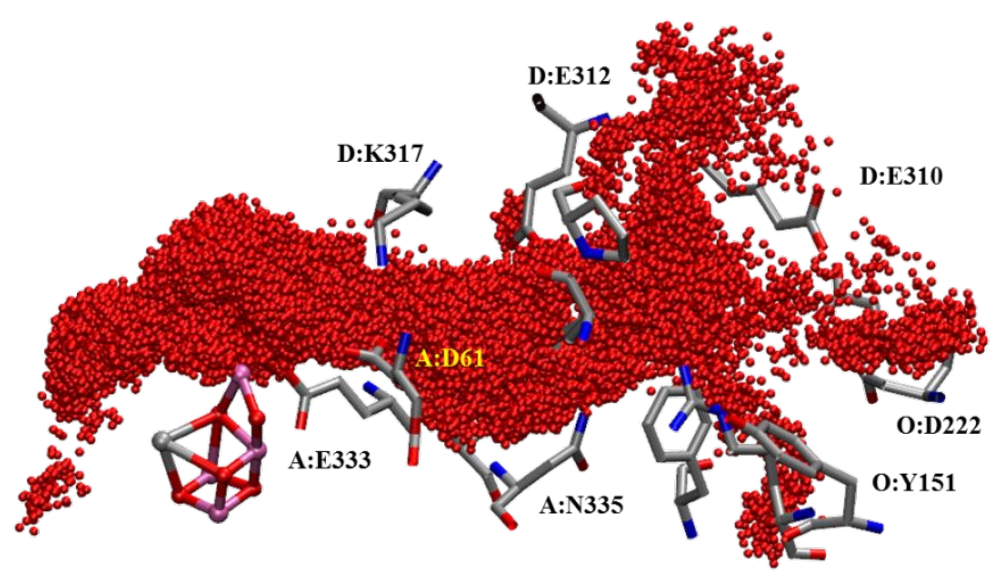

(c)

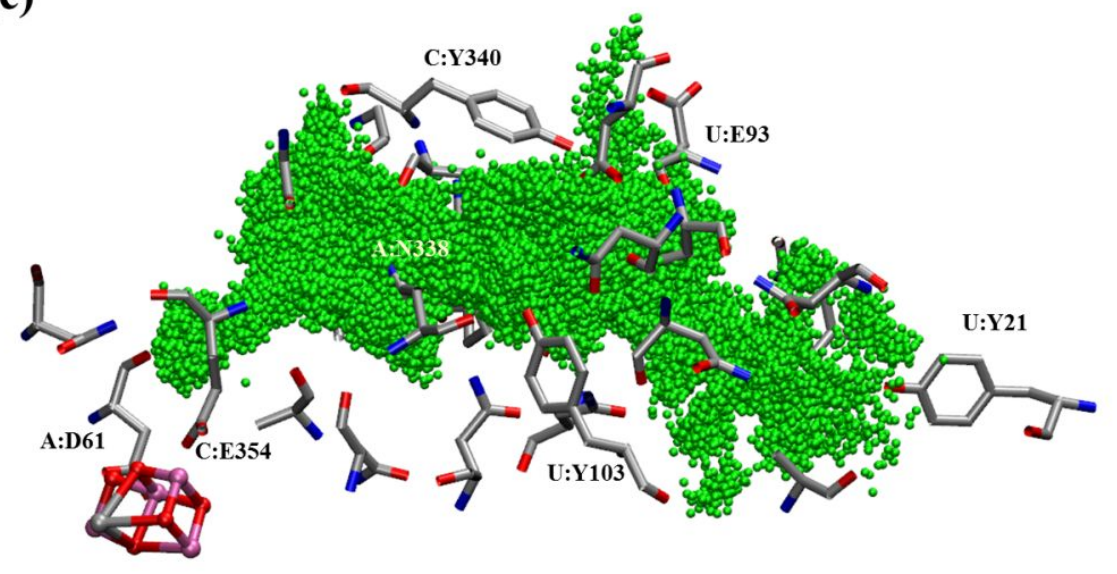


(d)

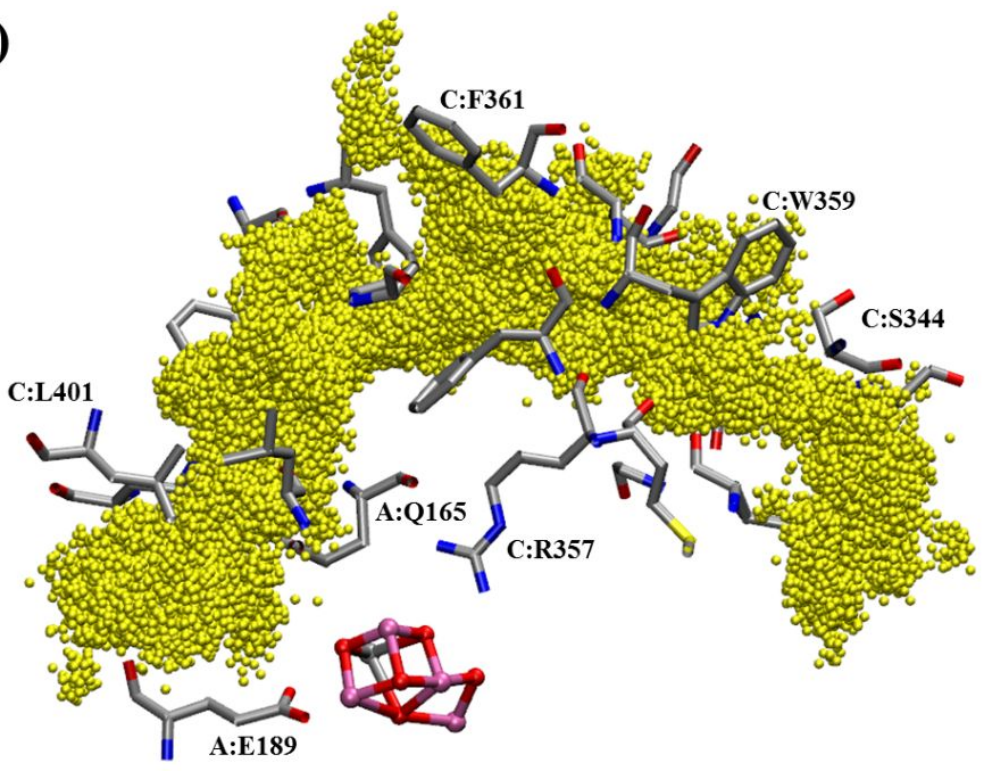

(e)

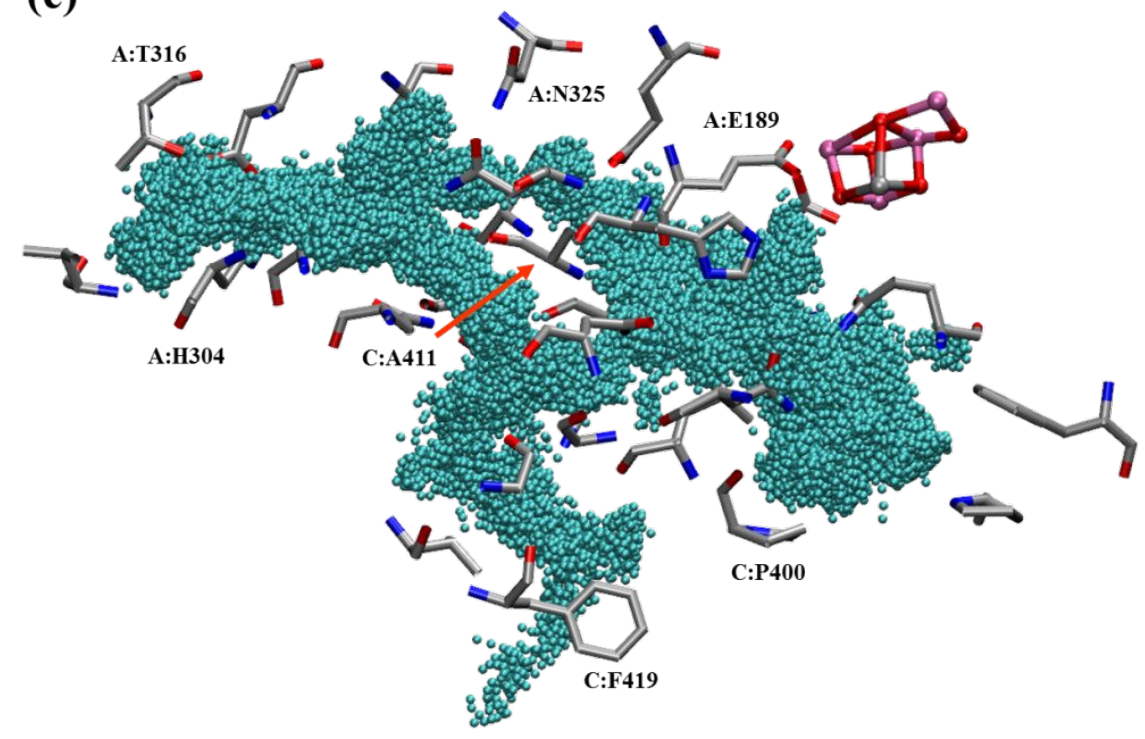

Figure S2. Detail of water distribution on the five pathways. 

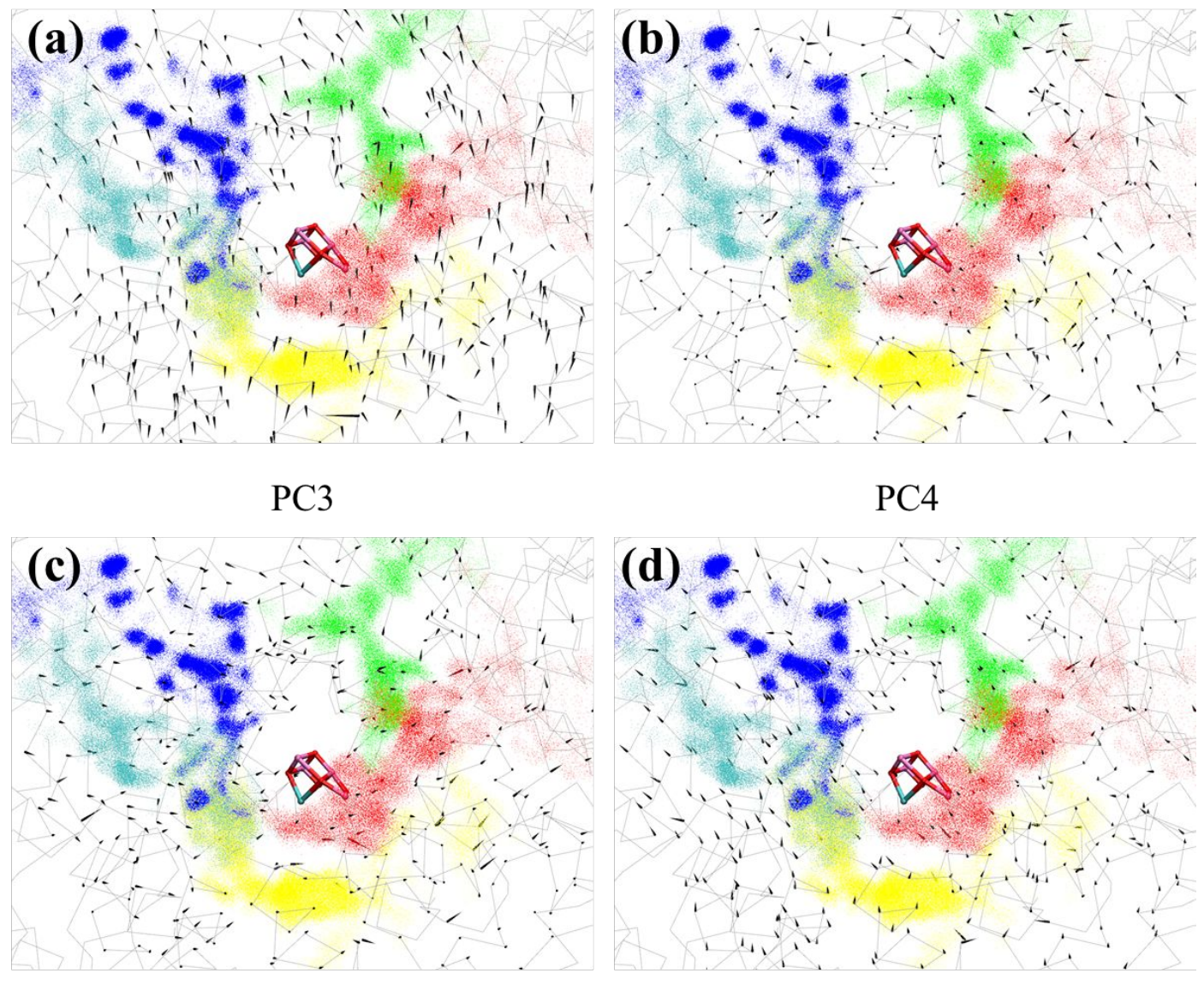

PC5

PC6

Figure S3. Principal components of $\mathrm{C} \alpha$ atoms. (a) The third, (b) the forth, (c) the fifth, and (d) the sixth principal components (PC) are described by cones colored in black. The distribution of water molecules independently forms Pathway1, Pathway2, Pathway3, Pathway4 and Pathway5, colored in blue, red, green, yellow and cyan, respectively. 


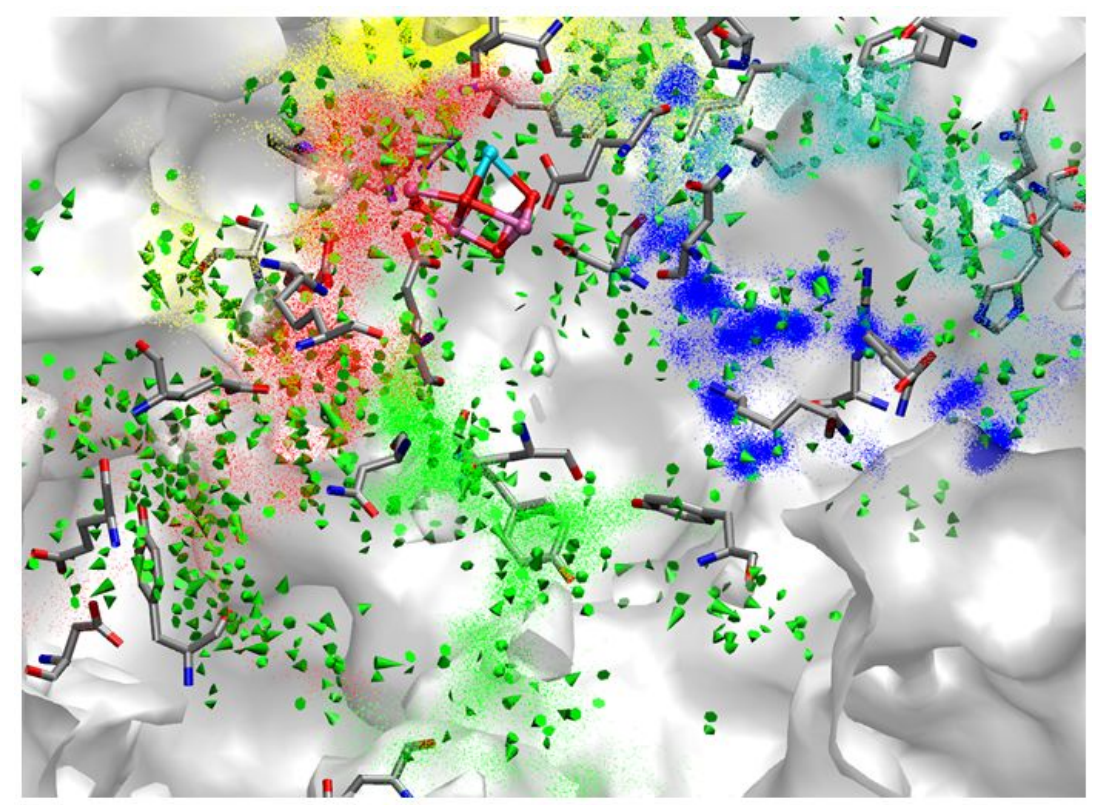

Figure S4. Direction of water molecules in the water pathways. The direction of water molecules on the grid was mapping on the five water pathways. On each grid, the vectors of $\mathbf{x}_{n}\left(=x_{n}-x_{n-1}\right)$ are accumulated and representative as a corn. The length of corn scaled 20 times of the original vectors. The colors of water pathways are the same as the Figure 3 (See caption of Figure 3). 


\section{Descriptions of supporting files.}

4ub6.fit.oex.pdb: OEC structure fitted to the initial structure of MD simulation.

4ub6.fit.pdb: PSII structure fitted to the initial structure of MD simulation.

Path1.xyz: XYZ file of Pathway1.

Path2.xyz: XYZ file of Pathway2.

Path3.xyz: XYZ file of Pathway3.

Path4.xyz: XYZ file of Pathway4.

Path5.xyz: XYZ file of Pathway5.

wat.grid.30.pdb: Water distribution within $30 \AA$ from the $\mathrm{Mn}_{4} \mathrm{O}_{5} \mathrm{Ca}$ cluster.

thylakoid.zip: AMBER parameters for the lipids consisting of the thylakoid membrane. 